DOI:

http://dx.doi.org/10.15448/1983-4012.2017.1.28053

\title{
PERCEPÇÃO COMO FONTE DE CRENÇAS JUSTIFICADAS
}

\author{
Perception as Source of Justified Beliefs
}

Carlos Augusto Sartori *

Resumo: O fundacionismo epistêmico alega existir uma categoria de crenças, as crenças básicas, aptas a interromper com legitimidade a cadeia das justificações. No caso das crenças perceptuais, o regresso epistêmico retrocede até uma crença cuja justificação depende da própria experiência sensorial. A ideia subjacente é que as crenças enraizadas ou baseadas na percepção são justificadas e constituem conhecimento em virtude desse enraizamento ou embasamento. Seguindo Audi e Huemer, o problema que se pretende discutir é como a percepção nos fornece acesso ao mundo exterior e como a percepção fornece justificação para as crenças sobre o mundo exterior.

Palavras-chave: Percepção, Justificação, Fundacionismo epistêmico.

\begin{abstract}
Epistemic foundationalism claims that there is a category of beliefs, the basic beliefs, able to stop adequately the justification chain. Taking perceptual beliefs, the epistemic regress goes back up to find a belief whose justification depends on the very perceptual experience. The underlying idea is that beliefs grounded or based on perception are justified and constitute cases of knowledge in virtue of this ground or base. Following Audi and Huemer, the problem we aim at discussing is how perception provides access to the external world and how perception yields justification for beliefs about the external world.
\end{abstract}

Keywords: Perception, Justification, Epistemic foundationalism.

* Professor no Departamento de Filosofia da Universidade Federal de Santa Maria. E-mail: carlos.augusto.sartori@gmail.com.

\begin{tabular}{|c|c|l|l|l|l|}
\hline intuitio & $\begin{array}{c}\text { ISSN } \\
1983-4012\end{array}$ & Porto Alegre & Vol.10 $-\mathrm{N}^{\circ} .1$ & $\begin{array}{l}\text { Julho } \\
2017\end{array}$ & p. 04-14 \\
\hline
\end{tabular}


Vou assumir aqui, seguindo longa tradição, a definição de conhecimento como crença verdadeira justificada. Não vou considerar as complicações tipo-gettier dessa definição. Vou também assumir que o fundacionismo epistêmico é a melhor alternativa de explicação da nossa estrutura cognitiva. Com isso, temos uma estrutura linear de justificação, tal que a cadeia justificatória retrocede até o ponto de encontrar uma crença básica, uma crença cuja justificação não depende de outras crenças. Como vou tratar de crenças sobre o mundo exterior, a cadeia retrocede até uma crença cuja justificação depende da própria experiência sensorial. A percepção é o método ou o processo que me permite ter acesso aos objetos do mundo exterior e suas propriedades. Assim, se é possível eliminar qualquer perspectiva cética sobre o assunto, podemos considerar a percepção fonte legítima de formação de crenças sobre o mundo exterior: as minhas crenças enraizadas ou baseadas na percepção são justificadas e constituem conhecimento em virtude desse enraizamento ou embasamento. O problema que se pretende discutir é como a percepção nos fornece acesso ao mundo exterior e como a percepção fornece justificação para as crenças sobre o mundo exterior

Suponha que eu esteja trabalhando no meu computador e ouça o miado de um gato. Então, eu olho através da janela e vejo um gato branco no telhado da casa vizinha. Ouvir o miado do gato e ver o gato branco no telhado são experiências perceptuais. De acordo com Audi (2011), há, pelo menos, quatro elementos envolvidos na percepção: (i) aquele que percebe, (ii) o objeto percebido, (iii) a experiência sensorial e (iv) a relação entre o objeto percebido e aquele que o percebe. Esses quatro elementos expressam o que se entende por análise tradicional da percepção. De outra maneira, junto com Huemer (2001), podemos colocar que, se $S$ percebe $x$, então:

1. $S$ está num certo estado mental, uma experiência perceptual;

2. O objeto da experiência perceptual de $S$ existe e satisfaz, mesmo que aproximadamente, o conteúdo desse estado perceptual;

3. Existe uma conexão apropriada entre o objeto e o estado perceptual.

A experiência perceptual (ou experiência sensorial), conforme Huemer (2001), é "definida como o componente mental, puramente interno, da percepção" (p. 58). Ora, se eu vejo um gato branco no telhado, poderia dar-se que essa experiência sensorial acontecesse mesmo que não houvesse qualquer gato branco no telhado. Nesse caso, porém, não se trataria de um caso de percepção no sentido qualificado que a análise de Huemer pretende estabelecer, já que para perceber seria necessário satisfazer a condição 2, a existência do objeto correspondente ao conteúdo da experiência sensorial. Trata-se, portanto, de um caso de alucinação. Segue-se disso que, "a existência de uma percepção implica a existência de uma experiência perceptual, mas a existência de uma experiência perceptual apenas implica a existência ou de uma percepção ou de uma alucinação" (Huemer, 2001, p. 58). Não há distinção, portanto, entre a experiência perceptual no caso da percepção de um gato branco no telhado e a experiência perceptual no

\begin{tabular}{|c|c|c|c|c|c|}
\hline intuitio & $\begin{array}{c}\text { ISSN } \\
1983-4012\end{array}$ & Porto Alegre & Vol.10 - No.1 & $\begin{array}{l}\text { Julho } \\
2017\end{array}$ & p. 04-14 \\
\hline
\end{tabular}


caso de alucinação de um gato branco no telhado. Quando eu percebo o gato branco no telhado, estou num estado mental (a experiência sensorial) puramente interno, cujo conteúdo é "estou vendo um gato branco no telhado", e quando alucino o gato branco no telhado, estou num estado mental (a experiência sensorial) puramente interna, cujo conteúdo é "estou vendo um gato branco no telhado". Portanto, nem toda experiência perceptual requer a existência de um objeto, mas para perceber, no sentido que queremos qualificar aqui, esse objeto é requerido.

Quanto à condição 2, precisamos esclarecer que a experiência sensorial consiste em um estado mental representacional, ela representa a realidade: o conteúdo da experiência sensorial é um certo estado de coisas possível. O fato de que um estado seja representacional não requer que seu objeto exista. Podemos imaginar e enunciar proposições sobre cavalos alados e unicórnios, mesmo que não existam cavalos alados e unicórnios. Mas a condição 2 da análise tradicional da percepção requer que, para $S$ perceber, haja um objeto que satisfaça o conteúdo do estado sensorial. Nesse sentido, para que um estado sensorial seja um caso de percepção, a experiência sensorial tem que ser um caso de apreensão, que Huemer define como "uma espécie particular de representação (...) representações mentais. Elas [as apreensões] também têm um outro traço definidor e interessante: apreensões representam seus conteúdos como atualizados. Esse traço eu refiro como sua 'assetividade"” (2001, p. 53). Então, se eu percebo que há um grato branco no telhado, isso implica que existe um gato (ou algo semelhante a um gato) que tem certas propriedades. De fato, às vezes as coisas não são do mesmo modo como as percebemos. Os célebres exemplos das linhas de Müller-Lyer e da vareta no copo d'água ilustram situações de engano ou ilusões, mas isso não quer dizer que não percebemos as coisas (as linhas e a vareta, no caso). Então, mesmo que eu perceba as linhas com tamanhos diferentes (quando na verdade elas têm o mesmo tamanho) e veja a vareta dobrada no copo d'água (quando na verdade ela não está dobrada), ainda assim há uma satisfação aproximada do conteúdo da minha experiência sensorial. Eu percebo que as linhas têm tamanhos diferentes porque é assim que as linhas se apresentam para mim; eu percebo a vareta dobrada no copo d'água porque é assim que a vareta se apresenta a mim. O conteúdo da minha experiência sensorial, nos dois casos, é satisfeito pelo modo como as coisas se apresentam para mim; portanto, há duas linhas e há uma vareta no copo d'água assim-e-assim que satisfazem o conteúdo da minha experiência. Todavia, não houvesse gato branco no meu campo de visão, ou as linhas de Müller-Lyer induzissem a uma experiência visual completamente diferente (eu as veria girando rapidamente, por exemplo), não estaríamos dispostos a dizer que estou percebendo um gato branco no telhado ou estou percebendo as linhas de Müller-Lyer.

A condição 3 requer conexão apropriada entre o objeto e o estado intencional. Essa conexão apropriada é uma relação causal entre o objeto e a experiência sensorial. Assim, eu percebo que há um gato branco no telhado somente se houver um gato branco no telhado que causa a minha experiência sensorial, cujo conteúdo é "eu estou vendo um gato branco no telhado": "algum tipo de conexão causal

\begin{tabular}{|c|c|c|c|c|c|}
\hline intuitio & $\begin{array}{c}\text { ISSN } \\
1983-4012\end{array}$ & Porto Alegre & Vol.10 $-\mathrm{N}^{\circ} .1$ & $\begin{array}{l}\text { Julho } \\
2017\end{array}$ & p. 04-14 \\
\hline
\end{tabular}


entre o objeto e a experiência [de $S$ ] é necessária para perceber o objeto" (Huemer, 2001, p. 65). Adaptando os quatro elementos indicados por Audi mencionados acima, teríamos que, se eu estou vendo (percebendo visualmente) um gato branco no telhado, então temos: aquele que percebe, eu; o objeto percebido, o gato branco no telhado; a experiência sensorial, minha experiência visual de formas e cores; e a relação causal pela qual o objeto produz a experiência sensorial no percebedor". Assim, conclui Audi, "[v]er o [gato branco no telhado] é aparentemente ter uma certa experiência sensorial como um resultado do impacto do [gato branco] na minha visão" (p. 17). ${ }^{1}$

Há três tipos de experiências perceptuais. A primeira delas é a percepção simples. A percepção simples consiste em ser afetado por uma porção da realidade através dos meus sentidos. Se meu aparelho auditivo estiver funcionando adequadamente e meu equipamento visual estiver funcionando como deveria estar, é irresistível que eu ouça o miado do gato e que eu veja o gato no telhado, e isso mesmo que eu não reconheça aquele ruído como o miado de um gato e não reconheça aquilo que se me apresenta visualmente como um gato branco no telhado, talvez devido à minha falta de conceitos para formar as proposições correspondentes. Isso vale para todos os sentidos: tenho experiências visuais, experiências auditivas, experiências olfativas, experiências táteis e experiências gustativas. Se estou familiarizado com laranjas, então a minha experiência visual é de uma laranja, eu sinto o gosto de laranja, eu sinto o odor característico de laranja, e poderia produzir relatos sobre essas experiências como sendo experiências relativas a laranjas. Todavia, todas essas experiências poderiam me ocorrer de forma idêntica ainda que eu não dispusesse de conceitos para classificá-las. Nesse caso, embora as experiências me ocorressem, não saberia produzir relatos a respeito delas. Além disso, há outra situação em que as minhas percepções ocorrem dessa maneira simples. Se estou andando por uma rua movimentada, sou afetado por vários ruídos, vários objetos, vários odores, etc., mas, como não estou focado nessas experiências, eu simplesmente percebo, mas nada dali decorre. Trata-se, então, no vocabulário de Audi, de percepção de algo.

Além da percepção simples, temos a percepção objetual, ou percepção-como ou percepção de ser assim-e-assim, que ocorre quando eu percebo algo que eu tomo como se fosse $\mathrm{x}$ com tais e tais propriedades. As linhas de Müller-Lyer podem servir aqui de exemplo: eu percebo as linhas como se elas tivessem tamanhos diferentes (eu as percebo sendo de tamanhos diferentes). Da mesma forma, eu poderia ver algo que eu tomo por um gato, como sendo branco e estando no telhado (eu percebo algo sendo branco e estando no telhado). A percepção objetual depende da percepção simples. É porque sou afetado visualmente pelas linhas de Müller-Lyer que posso dizer que as percebo de tamanhos diferentes; é porque sou afetado visualmente pelo gato que posso dizer que o percebo como sendo branco e como estando no

${ }^{1} \mathrm{O}$ exemplo de Audi diz respeito a um campo verde.

\begin{tabular}{|c|c|c|c|c|c|}
\hline intuitio & $\begin{array}{c}\text { ISSN } \\
1983-4012\end{array}$ & Porto Alegre & Vol.10 $-\mathrm{N}^{\circ} .1$ & $\begin{array}{l}\text { Julho } \\
2017\end{array}$ & p. 04-14 \\
\hline
\end{tabular}


telhado. Nesse caso, fazem-se necessários conceitos para classificar as propriedades que percebemos relativamente ao objeto.

Por fim, temos um terceiro modo de percepção: a percepção de fatos. Trata-se da percepção proposicional, a percepção que um estado de coisas se apresenta. Nessa modalidade, não percebo apenas as propriedades de ser branco e de estar no telhado que eu atribuo a algo que posso tomar por um gato mesmo que não o seja. Eu percebo que o gato é branco (e não algo que eu tomo por gato), percebo que o gato branco está no telhado, e assim por diante. Existe algo que eu percebo e que eu concebo como sendo um gato, do qual eu percebo também as propriedades de ser branco e de estar no telhado, o que me dispõe a asseverar que há um gato branco no telhado.

As experiências perceptuais nem sempre produzem crenças. As múltiplas experiências perceptuais que me ocorrem quando estou passeando por uma rua movimentada normalmente não estão no foco da minha atenção e, como não volto a atenção para elas, não formo as crenças correspondentes (ainda que essas experiências passem a estar disponíveis para a formação de crenças posteriormente). Também não é possível formar crenças com base na experiência se não domino os conceitos relevantes para atribuir propriedades e formular as proposições correspondentes às experiências perceptuais. Portanto, percepções simples não são suficientes para formar crenças. Além disso, a percepção não fornece sempre justificação para as crenças que formo com base nela. Razões podem se apresentar para eu pensar que estou tendo problemas auditivos e que, por isso, o miado do gato não está presente, ou que estou tendo interferências na minha visão e que não há gato nenhum no telhado. Esses possíveis problemas auditivos e essas interferências possíveis no meu campo de visão seriam anuladores de justificação e, se eu formasse as crenças de que há um gato miando nas proximidades e de que há um gato branco no telhado nessas condições, eu as formaria injustificadamente. A percepção é fonte de justificação somente se não há outras crenças que se opõem a ela, sejam crenças que já estão no meu sistema ou informações que se apresentam a partir de outras fontes no momento de formação das crenças. Audi (2002) tratou isso como dependência negativa: “[...] essa dependência da percepção de fatores que estão além da experiência perceptual é o que chamamos de dependência negativa; ela não mostra que a percepção não é uma fonte de conhecimento, mas apenas que (pelo menos) às vezes a fonte pode estar de alguma maneira bloqueada” (p. 73).

Se eu ouço claramente o miado de um gato e vejo claramente que há um gato branco no telhado, a clareza dessas experiências perceptuais me autoriza a formar as crenças correspondentes. Por certo, eu também estou habilitado a formar crenças autorreferenciais a partir dessas experiências: as crenças de que eu estou ouvindo o miado do gato e de que eu estou vendo o gato branco no telhado. À primeira vista, eu sei que tem um gato miando nas proximidades e sei que há um gato branco no telhado, e também sei que estou ouvindo o miado de um gato e sei que estou vendo um gato branco no telhado. E sei disso baseado na minha experiência perceptual. Há um enraizamento da minha crença na minha experiência perceptual.

\begin{tabular}{|c|c|l|l|l|l|}
\hline intuitio & $\begin{array}{c}\text { ISSN } \\
1983-4012\end{array}$ & Porto Alegre & Vol.10 $-\mathrm{N}^{\mathrm{o}} .1$ & $\begin{array}{l}\text { Julho } \\
2017\end{array}$ & p. 04-14 \\
\hline
\end{tabular}


Essas minhas experiências perceptuais são a base que sustenta as minhas crenças e são também os fatores justificacionais das minhas crenças. Assim, dizer que uma crença é fundada ou enraizada ou baseada numa experiência perceptual é o mesmo que dizer que a crença resulta da experiência perceptual, ou, dito de outra forma, que a experiência perceptual causa a crença: é a experiência perceptual que produz aquela crença. As crenças de que há um gato miando nos arredores e de que há um gato branco no telhado e as crenças de que eu estou ouvindo um gato miar e de que estou vendo um gato branco no telhado "são fundadas causalmente, justificacionalmente e epistemicamente na minha experiência perceptual. Elas são produzidas pela experiência, justificadas pela experiência e constituem conhecimento em virtude dessa experiência" (2011, p. 16).

É importante observar que uma experiência perceptual não ocorre isoladamente. Ao ver o gato branco no telhado, além de formar essa crença, eu poderia também ter formado as crenças de que o telhado tem a cor marrom, de que a casa é branca, etc. Nota bem Audi (2001) que uma experiência perceptual "é um fundamento tanto de crenças que eu tenho como para uma multiplicidade de crenças que eu poderia ter mas não formei” (p. 13-14). Assim, baseado na experiência perceptual de ver o gato no telhado, eu também teria justificação para formar as crenças de que o telhado tem a cor marrom, que a casa é branca, etc., e, pelo fato de que formar essas crenças com base naquelas experiências é consistente com a minha racionalidade, eu deveria formá-las se as proposições em questão me ocorressem. Assim, a experiência perceptual é fundamento das crenças, indiferentemente de se as crenças que ela pode justificar são formadas ou não. Nesse caso, a experiência perceptual é "como uma fundação sobre a qual não há nada construído, mas que está pronta para sustentar uma estrutura” (Audi, 2011, p. 18). Dessa forma, as crenças de que o telhado tem a cor marrom, de que a casa é branca, etc., são crenças fundadas perceptualmente: elas resultam do fato de eu ver que o telhado tem a cor marrom, que a casa é branca, etc., embora as crenças, inicialmente, não tenham sido formadas com a experiência visual. Todos os sentidos têm essa capacidade de ser fundamento de crenças, mesmo que crenças não sejam formadas. Podemos chamar isso de disposição para crer, e podemos acrescentar que "[n]ossa justificação para crer em alguma coisa pode preceder a própria crença, embora alguns fundamentos para a justificação nunca resultem em alguma crença" (Audi, 2001, p. 14).

A percepção simples é constituinte da percepção objetual e da percepção proposicional, mas é importante distingui-las devido à relação que elas têm com a justificação. Perceber objetualmente e perceber proposicionalmente me habilitam a formar crenças nos conteúdos dessas percepções. Para formar crenças, já foi dito, dependerei dos recursos conceptuais de que disponho. Se eu não tivesse o conceito de gato, o conceito de branco e o conceito de telhado, eu não seria capaz de formar as crenças de que o gato é branco e está no telhado e nem de que há um gato branco no telhado. A experiência visual estaria disponível para fundamentar essas crenças, já que poderia ver que há um objeto com certas características

\begin{tabular}{|c|c|l|l|l|l|}
\hline intuitio & $\begin{array}{c}\text { ISSN } \\
1983-4012\end{array}$ & Porto Alegre & Vol.10 $-\mathrm{N}^{\mathrm{o}} .1$ & $\begin{array}{l}\text { Julho } \\
2017\end{array}$ & p. 04-14 \\
\hline
\end{tabular}


num certo lugar, mas eu não poderia formar a crença correspondente ao conteúdo dessa experiência visual se essas experiências não ocorressem acompanhadas dos respectivos conceitos.

Algumas das crenças que eu formo a partir da percepção são crenças objetuais e outras são crenças proposicionais. Esses dois tipos de crenças correspondem a maneiras diferentes de eu estar relacionado com o objeto da minha percepção e a maneiras distintas de eu captar a verdade daquilo que constitui o objeto da crença que eu formo com base na percepção. Crenças objetuais dizem respeito ao objeto com o qual a minha crença está causalmente conectada. No exemplo dado, há um objeto do qual eu creio que é branco e que está no telhado. O objeto sobre o qual eu formulo a crença realmente existe (o gato) e minha experiência perceptual tem uma certa relação com ele, mas essa relação não implica que haja qualquer proposição na qual eu deveria crer a respeito do próprio gato. Eu posso crer que o gato é branco e está no telhado mesmo que eu esteja enganado e tome por gato algo artificial ou outra coisa. Eu poderia, portanto, pensar sobre o gato somente em termos do que eu acredito que o gato seja e não em temos do que o gato obviamente é. Através da percepção, eu formo crenças objetuais sobre os objetos a partir de perspectivas diferentes e eu formo um conceito do que o objeto é: "[um] modo básico de aprender sobre os objetos é encontrar verdades sobre eles (...) discriminando perceptualmente algumas de suas propriedades; formamos crenças objetuais (e outras) sobre eles (...) e finalmente chegamos a um conceito adequado do que eles são" (Audi, 2011, p. 20). Parece, então, que o conhecimento das propriedades perceptíveis é mais básico do que o conhecimento dos objetos que as possuem.

A verdade das crenças objetuais depende da verdade ou da falsidade daquilo em que se crê sobre o objeto. Dessa forma, se eu creio que o gato é branco e está no telhado, essa crença será verdadeira se aquilo que eu tomo como sendo um gato for branco e estiver no telhado. A indefinição do objeto aos quais eu atribuo certas propriedades nos casos de crenças objetuais faz com que não se possa, segundo Audi, simplesmente avaliar as crenças objetuais como verdadeiras ou falsas. Dependendo de se aquilo que eu creio sobre o objeto é verdadeiro ou falso, as crenças objetuais são também "precisas ou imprecisas". A minha atribuição de brancura e estar-no-telhado é verdadeira sobre aquilo que eu tomo por um gato e, mais do que isso, eu estou certo em fazê-lo. Mas, ainda que eu possa atribuir essas propriedades verdadeiramente, eu poderia fazê-lo mesmo que eu não soubesse que aquilo que eu estou vendo é um gato.

Como a crença objetual está ligada à percepção objetual, é nessa percepção que a crença fundamenta sua autoridade: a crença perceptual está enraizada na própria percepção que a causa. Sem excluir a possibilidade de que as crenças objetuais possam ter conteúdo proposicional (a crença de que há algo branco no telhado), as percepções objetuais podem constituir simplesmente casos de atribuições de propriedades que percebemos nos objetos, o que faz com que as crenças correspondentes sejam mais do que simplesmente verdadeiras: elas são verdadeiras relativamente aos objetos que percebemos. Assim, podemos dizer com Audi que "algumas percepções objetuais podem ser também plausivelmente

\begin{tabular}{|c|c|c|c|c|c|}
\hline intuitio & $\begin{array}{c}\text { ISSN } \\
1983-4012\end{array}$ & Porto Alegre & Vol.10 - No.1 & $\begin{array}{l}\text { Julho } \\
2017\end{array}$ & p. 04-14 \\
\hline
\end{tabular}


concebidas como simples atribuições de uma propriedade perceptível à coisa percebida", acrescentando que, nesse caso, "a crença objetual enraizada é verdadeira do objeto em vez de simplesmente verdadeira" (p. 21). Se a crença objetual está enraizada somente na percepção de propriedades do objeto, a percepção objetual fornece justificação apenas para as crenças relativas às propriedades percebidas, já que eu poderia não saber de que objeto se trata.

Uma crença proposicional, por outro lado, tem como conteúdo uma proposição. Eu creio proposicionalmente que há um gato branco no telhado porque essa crença está vinculada à minha percepção de que há um gato branco no telhado. É dessa vinculação com a percepção que a crença proposicional adquire sua autoridade: "a percepção proposicional produz conhecimento tanto do que é que percebemos como de algumas propriedades [do objeto que percebemos]" (p. 21). Do mesmo modo que a crença objetual, a crença proposicional está enraizada na percepção que a causa. Mas, diferentemente do caso das crenças objetuais, nas quais eu poderia estar enganado quanto ao objeto dos quais eu percebo certas propriedades, nas crenças proposicionais eu percebo as propriedades e as atribuo corretamente ao objeto que as possui e, sendo assim, a verdade ou a falsidade da crença dependerá da verdade ou da falsidade da proposição em que eu creio. Se eu creio que há um gato branco no telhado, essa crença será verdadeira se há um gato branco no telhado.

As crenças perceptuais têm um enraizamento (estão fundadas) na percepção de uma maneira que se estabelece uma conexão do sujeito com o mundo exterior e, por conta disso, a percepção garante a verdade das crenças. A minha crença visual de que há um gato branco no telhado está fundada na visão que eu tenho do gato de tal maneira que eu verdadeiramente vejo que o gato branco está no telhado. Sem dúvida, uma crença fundada na visão pode estar errada (pode ser uma ilusão de ótica, por exemplo), mas nesse caso a crença não está adequadamente conectada com a percepção porque eu não vejo o que parece que estou vendo. As linhas de Müller-Lyer me parecem ter tamanhos diferentes e eu genuinamente as vejo como se tivessem tamanhos diferentes. Mas se eu formasse a crença objetual ou a crença proposicional relativamente à diferença de tamanho das linhas, eu as formaria erradamente, porque não há diferença de tamanho das linhas para ser vista. Essas crenças, portanto, não estariam enraizadas na percepção de que as linhas têm tamanhos diferentes, pois elas não têm tamanhos diferentes. Isso reforça a distinção que se quer fazer, nesse amálgama de Audi e Huemer, entre experiência perceptual e percepção. A experiência perceptual é mais ampla e se refere a impressões que podem ir além dos sentidos. Dessa forma, se eu estivesse alucinando uma mesa diante de mim, não precisaria decorrer disso que eu estaria percebendo a mesa. Como diz Audi (2013), "se for um elemento na consciência não produzido pela percepção, mas, digamos, por um alucinógeno, poderia ainda justificar crer que há uma mesa diante de mim (...) mas não deveríamos assumir que alucinar uma mesa acarrete perceber uma mesa" (p. 183). A percepção, portanto, exigirá a conexão adequada entre o objeto (que deve existir) e a experiência perceptual correspondente.

\begin{tabular}{|c|c|c|c|c|c|}
\hline intuitio & $\begin{array}{c}\text { ISSN } \\
1983-4012\end{array}$ & Porto Alegre & Vol.10 $-\mathrm{N}^{\circ} .1$ & $\begin{array}{l}\text { Julho } \\
2017\end{array}$ & p. 04-14 \\
\hline
\end{tabular}


Disso se segue que a percepção proposicional e a percepção objetual são experiências verídicas e as crenças formadas com base nelas são crenças verdadeiras: “[p]erceber que e perceber ser, então, implicam crer (verdadeiramente) alguma coisa sobre o objeto percebido - e, assim, são factivas" (Audi, 2011, p. 22).

Parece claro que quando eu vejo alguma coisa isso me coloca em posição de formar pelo menos uma crença a respeito daquilo que eu vejo. Se eu vejo um lápis sobre a mesa parece que eu poderia formar a crença de que se trata de um objeto inanimado. De fato, há uma vasta série de crenças que poderiam ser formadas por uma simples percepção. O próprio Audi considera que a percepção tem um caráter informacional derivado do fato de que a percepção simples nos dá acesso cognitivo às informações obtidas através dela e, ao mesmo tempo, "grava" essas informações ainda que não formemos crenças relativas àquilo que simplesmente percebemos. Isso acontece porque nem toda percepção é conceptualizada e nem toda percepção é proposicional. "É por isso", diz Audi, "que não recebemos ou não estocamos [todas as informações] nos conteúdos das nossas crenças". E vai acrescentar que o conteúdo perceptual "é pelo menos em parte determinado pelas propriedades de que estamos sensoriamente conscientes ao ter aquela experiência [sensorial]" (2011, p. 25). Mas a percepção simples não acarreta crenças, como já vimos. A percepção simples apenas nos coloca na posição de perceber algo como se (objetual) ou na posição de perceber que (proposicional). A percepção tem caráter aspectual e representacional, isto é, quando eu percebo um objeto, eu o percebo através de suas cores, formas, etc., e a minha experiência perceptual representa esse objeto como tendo as propriedades que ele apresenta. Entretanto, perceber simplesmente um objeto não acarreta atribuir-lhe qualquer propriedade ou aspecto, diferentemente do que ocorre na percepção objetual e na percepção proposicional: esses dois tipos de percepção incluem atribuições e conceptualizações. A percepção objetual, de alguma forma, está incorporada na percepção proposicional. O conteúdo da percepção proposicional, perceber que $p$, inclui a proposição de que $p$ e seu conteúdo respectivo e também o próprio conteúdo da percepção objetual, isto é, as propriedades do objeto que está sendo percebido. ${ }^{2}$

Isso permite concluir que a evidência dos sentidos normalmente dá justificação para as crenças nos conteúdos apropriados àquela evidência: "ver um objeto (sempre) dá justificação prima facie para crer uma coisa ou outra sobre ele. Justificação prima facie é, grosso modo, justificação que prevalece a não ser que seja anulada" (Audi, 2011, p. 28). Fatores anuladores de $p$ são evidências que imporiam uma crença contrária à de que $p$ ou evidências que me permitiriam pensar que algo relativo ao processo de formação da crença não está ocorrendo de forma adequada (alguma evidência de que eu esteja alucinando, que a distância ou a iluminação não são apropriadas, etc.). Como nem toda percepção implica formar crenças, a

\footnotetext{
${ }^{2}$ A questão do conteúdo das experiências perceptuais gerou um desafio para o fundacionismo epistêmico: o dilema de Sellars. Sobre isso, ver Sartori, 2009.
}

\begin{tabular}{|c|c|l|l|l|l|}
\hline intuitio & $\begin{array}{c}\text { ISSN } \\
1983-4012\end{array}$ & Porto Alegre & Vol.10- No.1 & $\begin{array}{l}\text { Julho } \\
2017\end{array}$ & p. 04-14 \\
\hline
\end{tabular}


percepção fornece pelo menos justificação proposicional (justificação para crer que $p$, em contraste com crer justificadamente que $p$, que chamamos de justificação doxástica).

Assim, se eu vejo um gato branco no telhado e essa percepção visual causa a minha crença de que há um gato branco no telhado, essa crença é justificada, no sentido de que eu tenho uma boa razão para pensar que a minha crença de que há um gato branco no telhado é verdadeira: a própria experiência visual. Essa justificação, entretanto, é justificação que pode ser anulada, e, por isso, apenas justificação prima facie. Segue-se disso que poderíamos adotar o seguinte princípio para a justificação das crenças perceptuais: normalmente, uma crença que está enraizada (no sentido de ter conexão causal adequada) na percepção objetual ou na percepção proposicional é uma crença prima facie justificada. Sendo prima facie, poderá encontrar anuladores, e, portanto, podemos dizer que uma crença perceptual é justificada sempre que se crê em algo do tipo que a experiência perceptual parece mostrar, desde que tudo o que concerne à experiência esteja ocorrendo de modo aparentemente normal.

Ora, eu poderia alucinar um gato branco no telhado (num caso em que não há gato nenhum no telhado) e, desde que nada me permitisse considerar a possibilidade da alucinação, eu estaria justificado em crer que há um gato branco no telhado. Nesse caso eu teria formado uma crença falsa, ainda que justificadamente. Eu poderia, por outro lado, alucinar um gato branco no telhado (mas, nesse caso, há um gato branco no telhado) e, desde que nada me permitisse considerar a possibilidade da alucinação, eu estaria justificado em crer que há um gato branco no telhado. Nesse caso eu teria formado uma crença verdadeira, mas por acaso, já que o que causa a minha crença não é a presença do gato. Assim, embora eu tenha justificação em ambos os casos, eu não terei conhecimento. No primeiro caso, devido à falsidade da crença; no segundo, devido à acidentalidade da formação da crença verdadeira. Se, por um lado, conseguimos postular um princípio para a justificação das crenças perceptuais, a mesma facilidade não se dará para postular um princípio para o conhecimento de proposições perceptuais. Um princípio de justificação não precisa excluir a possibilidade de falsidade da proposição na qual eu creio, mas um princípio epistêmico, um princípio relativo ao conhecimento, terá que excluir fatores conducentes à falsidade, uma vez que não é possível ter conhecimento de proposições falsas. À primeira vista, entretanto, pelo menos nos casos normais, podemos estabelecer que a percepção objetual e a percepção proposicional permitem formar crenças que constituem casos de conhecimento: normalmente, uma crença que está enraizada (no sentido de ter conexão causal adequada) na percepção objetual ou na percepção proposicional é uma crença que constitui conhecimento. Se tudo o que concerne à experiência perceptual estiver ocorrendo de modo aparentemente normal, então a percepção me permite acessar o mundo como ele é.

Enfim, parece que formar crenças a partir da percepção objetual e formar crenças a partir da percepção proposicional são modos mais precisos de formação de crenças do que formá-las a partir do que

\begin{tabular}{|c|c|l|l|l|l|}
\hline intuitio & $\begin{array}{c}\text { ISSN } \\
1983-4012\end{array}$ & Porto Alegre & Vol.10 $-\mathrm{N}^{\circ} .1$ & $\begin{array}{l}\text { Julho } \\
2017\end{array}$ & p. 04-14 \\
\hline
\end{tabular}


as coisas simplesmente parecem ser. A tese de que as crenças formadas por simples aparências são prima facie justificadas ganhou força com Huemer (2001 e 2007) e vem sendo amplamente debatida como forma de sustentação da teoria fundacionista da justificação epistêmica. Não é o propósito aqui discutir essa teoria que ficou conhecida como conservadorismo fenomênico, mas, embora eu pudesse formar crenças a partir de como as coisas simplesmente me parecem ser sem prejuízo da minha racionalidade, as simples aparências podem não fornecer um grau suficiente de sustentação para que as crenças tenham justificação adequada, e, em consequência, possam constituir conhecimento. Assunto para outra oportunidade.

\section{Referências}

AUDI, Robert. The architecture of reason. Oxford: Oxford U. P., 2001.

AUDI, Robert. "The sources of knowledge”. In: MOSER, Paul (ed.) The Oxford handbook of epistemology. Oxford; New York: Oxford U.P., 2002. p. 71-94.

AUDI, Robert. Contemporary Foundationalism. In: POJMAN, Louis (ed.). The theory of knowledge. 3rd. ed. Belmont, CA: Wadsworth. Publishing, 2003. p. 174-82.

AUDI, Robert. Epistemology: a contemporary introduction to the theory of knowledge. London; New York: Routledge, 2011. 404p.

AUDI, Robert. Doxastic innocence: phenomenal conservatism and grounds of justification. In: TUCKER, Chris (ed.). Seeming and justification. New essays on dogmatism and phenomenal conservatism. New York, NY: Oxford U. P., 2013. p. 182-201.

HUEMER, Michael. Skepticism and the veil of perception. Lanham, MD: Rowman \& Littlefield, 2001.

HUEMER, Michael. Compassionate phenomenal conservatism. In: Philosophy and Phenomenological Research. Vol. 74, n. 1, 2007. p. 30-55.

SARTORI, Carlos A. A justificação prima facie das crenças perceptuais. In: Anales del 1er Congreso de la Sociedad Filosófica del Uruguay. Montevideo, SFU, 2012, vol. 1, p. 482-491.

SARTORI, Carlos A. O dilema de Sellars: desafio ao fundacionismo epistêmico. In: Veritas, vol. 54, n. 2, 2009. p. 96-108.

\begin{tabular}{|c|c|c|c|c|c|}
\hline intuitio & $\begin{array}{c}\text { ISSN } \\
1983-4012\end{array}$ & Porto Alegre & Vol.10 $-\mathrm{N}^{\circ} .1$ & $\begin{array}{l}\text { Julho } \\
2017\end{array}$ & p. 04-14 \\
\hline
\end{tabular}

